\title{
La historia interminable: Langostino y Mangucho y Meneca en Patoruzito (1945-1950)
}

\section{Gandolfo, Amadeo}

Resumen:

La aparición de la revista Patoruzú en 1936 marca el inicio de una de las editoriales de historieta más prosperas de la Argentina, aquella comandada por Dante Quinterno. Durante mucho tiempo la compañía por él fundada sería el paradigma de una organización moderna del trabajo de las viñetas y de una línea estética: dibujos redondeados, líneas claras, personajes amables, historias donde el bien siempre triunfa. En 1945 el empresario decidió expandir su línea con el agregado de una revista de historietas apuntada a los más pequeños: Patoruzito. Esta se presentaba como una revista que deseaba ofrecer en cada página una nueva aventura, historias que se continuában de forma eterna,

\section{Cuadernos del Centro de Estudios de} Diseño y Comunicación N ${ }^{074}$

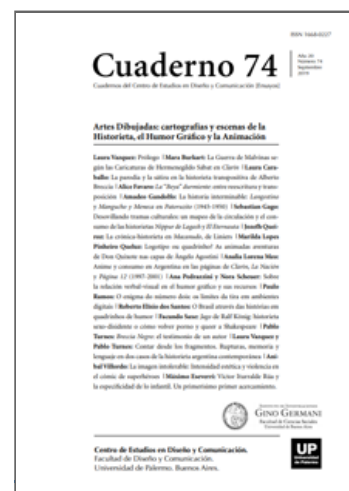

ISSN: 1668-0227

Artes Dibujadas:

cartografías y

escenas de la

Historieta, el Humor

Gráfico y la

Animación

Año XX, Septiembre 2019, Buenos

Aires, Argentina | 256 páginas

descargar PDF

ver índice de la publicación

Ver todos los libros de la publicación

compartir en Facebook

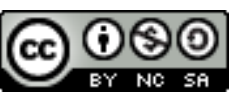

Esta obra está bajo una Licencia Creative Commons Atribución-NoComercialCompartirlgual 4.0 Internacional

personajes incansables. En un principio combinó material nacional y estadounidense, adquirido mediante syndicates. Pero pronto desarrolló a sus propios dibujantes estrella, entre ellos la dupla que tratamos aquí: Eduardo Ferro y Roberto Battaglia.

Palabras claves: Eduardo Ferro - Roberto Battaglia - Patoruzito

$\left(^{*}\right)$ Licenciado en Historia por la Universidad Nacional de Tucumán. Doctor en Ciencias Sociales por la Facultad de Ciencias Sociales de la Universidad de Buenos Aires. Jefe de Trabajos Prácticos en la materia optativa de la Carrera de Sociología (UBA), "El lado B de la sociología: Nuevas sociologías pragmático-pragmatistas y su reencuentro con viejas tradiciones", dirigida por Gabriel Nardacchione.

1. Una industria nacional 
Dante Quinterno representa uno de los modelos más acabados del empresario editorial dedicado a la historieta en Argentina. Hombre hecho a sí mismo, trabajador del plumín en redacciones y diarios durante antes de consagrarse como hábil editor y empresario, con aspiraciones multimediales y la ambición de establecer una verdadera empresa gráfica moderna.

Es notorio como la condición de dibujante y creador de Quinterno es prontamente abandonada en pos de la figura del empresario. Y como, si bien es conservador en lo político, es moderno en las formas y en su modelo industrial. Como menciona Laura Vazquez: "impugna la democratización de la vida política por un lado pero, por el otro, usufructúa los réditos del progreso, la industrialización y el proyecto burgués" (2012, p. 23) una combinación tan exitosa que hasta el día de hoy el recuerdo de su empresa adquiere caracteres míticos e "Ideología y mercado se conjugaron para revelar un repertorio iconográfico y narrativo que dejó su huella en el imaginario de los profesionales del medio y en el público lector" (2012, p. 25).

En el continuo enfrentamiento entre arte e industria que surca a la historieta desde su creación como lenguaje se puede decir que Quinterno es, en realidad, un artista de la industria. Quinterno creaba personajes y rápidamente los abandonaba en manos de otros dibujantes, pero mantenía la marca de origen y la firma: la autoría nunca era cedida. Quinterno, además, buscó, y durante un período prolongado lo logró, una factoría de producción. Como menciona Eduardo Ferro:

Cuando entré había el compromiso de cumplir un horario de dos y media a siete de la tarde. Nunca lo pude cumplir (...) En Quinterno había un reloj donde teníamos que firmar la entrada. Yo me rebelé y en lugar de firmar le empecé a hacer un dibujito (...) Al fin sacó el reloj y quedó el compromiso de cumplir el horario. Pero yo la verdad que nunca llegué antes de las cuatro... En una época, todas las tardes trabajábamos juntos los humoristas en un salón con seis escritorios (...) De cuatro a siete estábamos allí todos los días. (Sasturain, 1980, p. 84)

El modelo pareciera ser el del "shop" que surge durante la época dorada del comic book norteamericano, en los años 40 , en donde grupos de artistas hambrientos producían pá- ginas para una industria voraz. Pero hay que considerar que la revista Patoruzú, cabeza de lanza del imperio Quinterno, se inicia en 1936, un par de años antes del despegue del comic book. Quinterno es, además, pionero en la organización del trabajo de la historieta en Argentina. El modelo, entonces, era la redacción periodística, con su disciplina y su sistema jerárquico. Quinterno revisaba todas las páginas y las tiras antes de enviarlas a la imprenta, y si encontraba algo que no le gustaba exigía al colaborador que lo corrigiese de acuerdo a su visión. Quinterno buscaba el mayor didactismo y uniformidad con su mensaje estético e ideológico. Como menciona Oscar Steimberg hablando de la revista Patoruzito: "se experimenta la sensación de estar abandonando el campo de la creación narrativa para recorrer el de los textos escolares" (2013, p. 92).

El proyecto de Quinterno es conservador no solo en lo ideológico sino también en su estructura formal. Por las aventuras en donde siempre triunfan los buenos y también porque sus revistas se encontraban organizadas siempre en las mismas secciones fijas ordenadas de la misma manera, transparentando una férrea conducción editorial.

Esto nos proyecta a la discusión sobre el esquematismo en la historieta, sostenida entre continentes por Umberto Eco y Oscar Masotta. Eco, en su famoso análisis de Superman, esgrime el punto de vista de que las 
aventuras del superhombre forman parte de una banda de mobius sin principio ni final, el tiempo se encuentra indefinido y no hay conexión temporal entre una aventura y otra, Superman reinicia sus aventuras una y otra vez desde un punto cero, básico, al que siempre retorna y la muerte jamás lo alcanza. Esto refuerza una "estructura circular, estática, vehículo de un mensaje pedagógico sustancialmente inmovilístico" (1984, p. 287). Eco propone que contenido y estructura se refuerzan unos a otros y que generan efectos conservadores y de conformidad en su audiencia. El eterno retorno de lo mismo en Superman funciona como un marco dentro del cual los mensajes de una cultura conformista y repetitiva pueden ser volcados. Masotta, por su parte, le contesta que efectivamente las historietas son esquemáticas, pero que esto no necesariamente es malo, que es el contenido ideológico lo nocivo y que "lo que en ningún caso es recomendable hacer es deducir de las propiedades de la estructura sus efectos sobre los usuarios de los mensajes, esto es, inferir la función de la estructura" (2011, p. 308) y propone el efecto de la doble lectura como algo constitutivo del medio que evita la heterodirección del mensaje ya que "es como si exigiera (...) una decodificación 'en molinete', solo es posible tomarlos en serio a condición de reírse un poco de ellos y reírse de ellos a condición de tomarlos en serio" (2011, p. 310).

En este punto lo que nos interesa es otra condición del esquematismo: la repetición. Eco hace de la repetición un motivo de crítica y un principio último de la historieta. Pero, además, hay otro tipo narrativo que es muy común en la historieta, y que encontramos frecuentemente en tiras de prensa de los albores de la historieta como medio masivo: la sucesión continua e interminable de acontecimientos sin un orden premeditado pensado por el autor.

Aquí seguimos el trabajo de R.C. Harvey quién, en The Art of the Funnies, se propone una doble tarea: por un lado trazar una historia estética de las tiras diarias y dominicales en los Estados Unidos, tomando en consideración el cambio de los estilos de dibujo y la relación entre la historieta realista y la historieta humorística. Pero, por otro lado, esta evolución estética está indeleblemente asociada a la noción de narratividad y de acontecimiento, a la manera en que va desplegándose una serialización de la acción en aventuras largas, y como esto permite salir del acontecimiento aislado y narrado de forma repetitiva. Harvey destaca a Mutt \& Jeff como la primera tira que establece el formato: "se presentaba como una 'tira' de dibujos, su narrativa continuada día a día, y apuntaba deliberadamente a audiencias adultas" y "una vez que la decisión había sido tomada de formatearlos en 'tiras' y publicarlos diariamente, el resto -continuidad, incluso el público adulto- sigue de forma lógica" (1994, pp. 41-42).

Sin embargo, a pesar de una rudimentaria continuidad, Mutt y Jeff seguía entroncada en la lógica de las tiras "de un solo chiste". Mutt intentaba engañar a alguien, mientras que Jeff, eterno bonachón y soñador, arruinaba sus planes con su inocencia. Como dice Harvey, muchas de las primeras tiras contaban con "Un humor que residía en poco más que en un sola situación, presentada una y otra vez, cada presentación una variación de la primera y básica situación" (1994, p. 48). Esto cambia con la aparición de la tira de aventuras:

...no le tomó demasiado tiempo a los cartoonists darse cuenta que un cliffhanger ganaba en poder emocional si los personajes abandonados estaban en peligro (...). El peligro que atenta contra la vida por consiguiente significa acción que amenaza a la vida; resumiendo, aventura. (1994, p. 70)

Destaca que el primer ejemplo de esta tradición es Wash Tubbs y Captain Easy, de Roy Crane, sobre el cual además destaca su condición híbrida en el dibujo: "La combinación de Crane de lo fantástico y lo auténtico (...) hizo de Wash Tubbs única en la página de comics” (1994, p. 80). 
Esto nos retrae a la caracterización propuesta por Federico Reggiani en cuanto al dibujo de historietas realista y humorístico. Reggiani, al igual que Harvey, encuentra en el dibujo realista se asocia fuertemente con "la línea que lleva de las historietas primitivas a una adaptación a un modelo distinto, a la construcción de relatos extensos en los que prime la narración sobre el efecto humorístico de corto plazo" (2012, p. 131). ¿Pero qué sucede con casos en los cuales la aventura se encuentra dibujada en un estilo caricaturesco, humorístico?

En 1945 Dante Quinterno saca a la calle Patoruzito. A diferencia de Patoruzú, que ya tenía una década, estaba apuntada de forma directa a los niños. El objetivo era producir una revista de aventuras competitiva, profesional y moderna.

“La revista PATORUZITO será un nuevo semanario de grandes historietas, especialmente concebido para la juventud amante de las aventuras y un exponente de ese género del periodismo gráfico, por su cuidada presentación y seleccionada calidad de sus historietas". (Patoruzito \#1, 1945, p. 6)

La misma aunará lo mejor de la producción realizada en el interior de la editorial Quinterno con importantes reproducciones de tiras estadounidenses, algunas de gran renombre (como Flash Gordon), otras prácticamente olvidadas (Justicia Invisible, Hugo y su Autó- mata). Si contabilizamos la cantidad de series aparecidas en el primer número observamos 10 series nacionales contra 15 internacionales. Con el paso del tiempo este número se equilibrará y luego las extranjeras prácticamente desaparecerán, a la vez que la revista enflaquece por las restricciones de papel. La revista, asimismo, reproducía el formato rígido de su antecesora para adultos: todas las historietas aparecían siempre en las mismas páginas. Patoruzito nos brinda otra visión del proyecto editorial de Dante Quinterno: diversificación de públicos y de contenidos, reproducción esquematizada de un formato, producción a gran escala, una industria cultural masiva que tenga algo que ofrecer a cada miembro de la familia. Pero también un ojo atento al material y modelos extranjeros, que seguía con atención, resultando en una inteligente mezcla de material local y extranjero, que nos lleva a preguntarnos sobre la relación entre la historieta argentina y su par norteamericano. Como menciona Vazquez, la empresa de Quinterno debe ser entendida en tanto y en cuanto "sus estrategias de imitación de un modelo importado, el modo en que mixturó y se reapropió de un ideal hegemónico" (2012, p. 9).

Sin embargo, la revista alojaba en su interior a dos tiras muy inusuales para la factoría Quinterno: Langostino, marinero independiente de Eduardo Ferro, y Mangucho y Meneca, de Roberto Battaglia. Si tomamos en cuenta el ordenamiento espacial de la revista, llama la atención que la primera se publique en retiración de tapa y la segunda en retiración de contratapa, los márgenes, casi cayéndose de la revista, como indicando que no terminaban de pertenecer a la misma.

Ambas tiras privilegiaban la aventura interminable y absurda, la concatenación de eventos, la improvisación sobre la página y sobre los cuerpos dibujados, la multiplicación de personajes y escenarios extravagantes. ¿Cómo funcionaban ambas tiras en el interior del producto Quinterno, reglado y controlado? ¿Cómo construían su narratividad? ¿De qué manera graficaban la aventura? Intentaremos responder a estas preguntas en los siguientes apartados. Tomaremos en consideración los primeros años de aparición de las mismas, ya que ellos son aquellos en donde su lógica narrativa y exploratoria se establece del ensayo y error hasta la tipicidad.

\section{Langostino, marinero sin destino}


Eduardo Ferro fue uno de los dibujantes más duraderos y confiables en el interior del proyecto editorial de Quinterno. Entró a trabajar en Patoruzú en 1937, apenas un año luego de que iniciase su publicación y se desvinculó de la empresa en 1976, 40 años después. Durante este extenso período cumplió diversas tareas. llustró cuentos, almanaques, continuó series iniciadas por Quinterno (El Fantasma Benito), desarrolló ideas originales de su jefe (Cara de Ángel) y dibujó personajes originales entre los cuales se encuentra quién aquí nos ocupa: Langostino.

La carrera de Ferro aúna dos elementos en principio incompatibles. Por un lado una adscripción profesional al interior del proyecto Quinterno y en diversas redacciones de otras publicaciones periódicas de la época (su carrera se inició en el semanario deportivo La Cancha y también colaboró durante 17 años con La Razón), por otro, una gran espontaneidad en el trazo y la construcción narrativa y desparpajo en las entregas. Como le comentaba a Juan Sasturain en un clásico reportaje: "Por mi característica de entregar sobre el cierre, lo acostumbré a Quinterno a que no me viera los trabajos, ya que ni siquiera recorrían las vías normales de redacción: iban al taller" (1980, p. 84). Asimismo, sobre su experiencia trabajando en La Razón, comentaba que Peralta Ramos, editor del diario, un día lo citó y "dijo que estaba cansado de que yo entregara de a dos tiras, que me daba el lujo de parar 'La Razón', que el último cliché que faltaba era siempre mi tira y que los secretarios se quejaban" (1980, p. 86$)$.

Langostino, asimismo, surge de esta extraña conjunción entre profesionalismo al interior de una gran empresa gráfica y libertad creativa. Luego de ocho años de trabajar continuando o sobre ideas de Quinterno, para el lanzamiento de Patoruzito este le encarga que realice un personaje marítimo pero "me dejó hacer lo que yo quise. Él me pidió un navegante un poco aventurero y yo empecé a divagar a gusto" (Ferro, p. 1986). Así, se le ocurrió Langostino, que se publicó de forma ininterrumpida durante 740 semanas, hasta principios de los sesenta, momento en que Quinterno intentó una renovación de la revista y discontinuó la serie.

En la primera plancha en la que aparece, Langostino se encuentra cruzando pasajeros a lo largo del Río de la Plata en una barcaza precaria, juntando moneda sobre moneda para poder comprar quién será la única compañía de todas sus aventuras: Corina, un barco pequeñísimo, en el que apenas cabe su cuerpo, su cara ancha y sus brazos extensos. A partir de la adquisición de la barcaza, Langostino se embarca en un proceso de exploración aparentemente perpetuo.

La tira está construida sobre la base de la concatenación de acontecimientos y, al menos en sus primeros años, sobre un delicado proceso de improvisación de las aventuras. El mecanismo seguido por Ferro en un principio consistía en presentar una amenaza en los primeros cuadritos de la tira que era resuelta en los cuadritos centrales y en el último un final de suspenso que introducía un segundo elemento de peligro o sorpresa que sería continuado en el siguiente episodio. De esa forma, la tira adquiría una suerte de movimiento perpetuo, en el cual Langostino se encuentra continuamente arrojado a la acción y el imprevisto. El trazo de Ferro replica esta condición: volátil, curvilíneo, cinético, en cada cuadro se mueve un personaje o exclama un discurso. En los momentos en que Langostino navega, las olas son hipérbolas que cambian de dirección y arrojan al barquito hacia el siguiente cuadrito. Sin embargo, la disposición de la página es rígida, con cuadritos cerrados y bien definidos y poca experimentación en el trazado de la misma.

Las primeras 30 entregas aún no construyen una narratividad de largo alcance. Son más bien sucesiones de eventos inesperados. Aparece un pez espada, Langostino se salva, aparece una ballena, Langostino termina en 
una isla, lo persiguen los caníbales, aparece un mono gigante, el mono gigante se pelea con una serpiente, Langostino encuentra un tesoro. No hay una motivación que mueva al personaje más allá de la aventura por la aventura misma, del escape de una situación riesgosa para caer en otro punto límite.

A partir de la plancha 30 y hasta la 55 una lógica narrativa más extensa comienza a coagular. Langostino escapa de un prefecto que lo ha encerrado por desacato y encuentra un científico loco que le cambia la cara a la gente. Sin abandonar la concatenación de eventos disparatados, la tira comienza a adquirir motivaciones y conflictos que van más allá de la amenaza de la semana. Este proceso termina de encontrar forma con una larga secuencia que se inicia en la entrega 57 en donde un ave gigante roba a Corina y Langostino es secuestrado por dos científicos que quieren atraparla.

A partir de este momento la tira adquiere el carácter explorador, de descubrimiento de nuevas civilizaciones, islas y países por la cual se hizo famosa. En el período que consideramos Langostino viaja al Planeta de los Filipicus, al planeta de la Rara Avis, a la Isla de Bala (habitada por matones y ladrones armados), a Atomia (planeta de átomos donde Ferro despliega una imaginación visual deslumbrante y convierte a Langostino en música y partículas), a Balibali (territorio helado y, una vez más, repleto de malvivientes), a una isla sin nombre en donde diversas facciones se disputan el poder a través de la conspiración y la violencia y a Punchingbalia, tierra donde todos se encuentran obsesionados con el boxeo. Langostino, por momentos, adquiere motivaciones y objetivos. Viaja a la Isla de Bala debido a que a Corina se le rompió la cruceta y allí es el único lugar donde pueden arreglarla. Llega a Balibali siguiendo el impulso que le dicta una caja de música. En otras ocasiones, la lógica sigue siendo simplemente la simple profusión de eventos y aventuras.

Mucho de la manera en que la tira organizaba su narración tiene que ver con la forma en que Ferro la dibujaba:

Improvisaba totalmente (...) Como siempre entregaba tarde, llegué a hacerlo en dos horas... Miraba donde lo había dejado (...) y si no se me ocurría nada prolongaba la situación, le agregaba un parlamento filosófico y si llegaba al fin de la página sin cerrar la idea le incorporaba una nueva complicación. (Sasturain, 1980, p. 86)

Esto se percibe de forma muy clara en los continuos reversos de fortuna y carácter de muchos personajes. Un recurso muy utilizado por Ferro consiste en la revelación de un detalle previamente desconocido de alguna de sus creaciones que da sentido a una situación sorprendente, o el cambio de parecer que hace que malos se vuelvan buenos y viceversa. Langostino mismo, muy a menudo, es sometido a operaciones, presiones psicológicas, experimentos y brebajes que cambian su personalidad o lo dejan convaleciente o delirante durante episodios enteros.

Pero Langostino además de independiente es solitario. Ya lo mencionó Oscar Steimberg en su pionero análisis de la tira: "Langostino no es un marinero sin destino, sino con un negro destino: navegar a la deriva, solo, y toparse a cada paso con peligros que no entiende ni busca" (2013, p. 91). No hay personajes secundarios ni de soporte más allá de aquellos específicos a cada aventura. Corina apenas puede transportar a Langostino.

Esto produce una forma de narratividad que se encuentra a mitad de camino entre la repetición y la continua y asombrosa novedad. Langostino siempre se enfrenta a nuevos peligros, pero esos nuevos peligros se encuentran enmarcados en una lógica de la deriva que es siempre la misma. Incluso, como hemos mencionado más arriba, hay ciertas cualidades que se repiten de aventura a aventura: islas pobladas de personajes 
siniestros y malvivientes, interludios en el mar en los cuales se enfrenta a criaturas marinas, la pérdida de Corina, de su pipa o de algún otro objeto que lo define como personaje (porque Langostino no es solo Langostino, es Langostino con Corina), los desperfectos técnicos, las salvaciones providenciales a través de personajes circunstanciales.

Hay un tropo particular que se repite de forma insistente y es intrigante: Langostino siendo enjuiciado y castigado por las reglas de las sociedades a las cuales llega y no comprende. En la Isla de Bala, el juicio es llevado adelante por sepultureros y funebreros y el estrado donde se para el acusado tiene forma de guillotina (Patoruzito \#95-97, 1947). (Ver Figura 1)

En el Planeta de los Filipicus es encerrado en un tubo mientras sesiona un Tribunal Supremo de Alta Justicia frente al cual no puede ni apelar ni razonar (Patoruzito \#70-71, 1947). En Atomia le quitan las cuerdas vocales por alzar la voz con violencia y cuestionar el funcionamiento de un globo de percepción individual que transforma las cosas (Patoruzito \#118, 1948).

Langostino, sin embargo, es un alma inocente, que solo se ve arrojado a situaciones de enjuiciamiento y castigo por su desconocimiento elemental del funcionamiento de los países que visita. Desconocimiento lógico ya que sus aventuras no le dan tiempo más que para una aprehensión en la acción de la lógica del lugar que visita, urgido como se encuentra por los acontecimientos, y ya que jamás retorna, manteniéndose siempre en movimiento. No podemos evitar pensar: una persona del carácter y estilo de trabajo de Ferro, que privilegiaba la libertad y la improvisación, enmarcado en la férrea disciplina de una empresa como la de Dante Quinterno, ¿habrá encontrado una válvula de escape para la tensión entre ambos hechos colocando a su héroe en diversos juicios ridículos que replicaban su propia sensación de incomprensión y fastidio frente a una gran empresa y sus modos de trabajo?

Langostino pone marcha una narratividad en la cual la aventura no solo es lo inesperado y lo peligroso, sino también la deriva. Como dijo en un texto autobiográfico publicado en 1986: "Yo creo que lo principal era que me divertía haciendo una historieta loca y la dejaba que se hiciera casi sola" (Ferro, 1986). Langostino es similar a una historieta sui generis, una historieta que se construye de la misma manera para autor y lector: semana a semana, al calor de los acontecimientos, sin un destino ni un final programado, casi de forma automática. Ferro alguna vez la comparó con la poesía, y es cierto que contiene mucho lirismo bonachón y un aire ligero y reflexivo, pero la poesía contiene métricas y reglas también. En realidad se parece mucho más a la improvisación del artista callejero o, aún mejor, al voceo de un canillita que innova sobre los acontecimientos publicados en el más reciente periódico.

\section{Mangucho y Meneca o el espesor del absurdo}

Al lado de Ferro, autor que trabajó casi hasta el final de su extraordinariamente larga vida (murió en el 2011 a los 93 años), que fue rescatado como parte de un canon nostálgico de la historieta de humor y aventuras, y que aceptó y desempeñó su condición de trabajador de la historieta, Roberto Battaglia es poco menos que un misterio. Nacido en 1923, Battaglia desarrolló su actividad profesional en diversos medios, entre ellos Billiken, La Hora, Patoruzú, Crítica y por supuesto Patoruzito. Como correspondía a todo trabajador gráfico de la época la mayoría de las fotos que se conservan de él muestran un atildado y elegante caballero de traje y corbata, que no se sacaba el saco ni siquiera para dibujar en el estudio de Quinterno. 
Hacia mitades de los sesenta Battaglia emprendería el exilio hacia Estados Unidos, más precisamente Nueva York. Allí formó parte de una suerte de comunidad de dibujantes exiliados entre los que se encontraban Francho (Arnoldo Franchioni), Alfredo Olivera, Vic Martin, Narciso Bayón y Osvaldo Laiño. Pero con los años Battaglia, quién se retira por completo de la labor de dibujante, perdería contacto con todos estos expatriados, perdiéndose el rastro de su vida hasta que en el 2007 por intermedio de un sobrino se conocería que Battaglia había muerto dos años antes (Laiño, 2007). En su trayectoria observamos un voluntario retiro de la misma industria que le había servido de sustento justo en el momento en que esta entraba en su largo eclipse, un exilio personal y profesional y un borramiento de su nombre en el tiempo.

La obra más conocida y recordada de Battaglia es aquella que trataremos aquí: Mangucho y Meneca, que luego sería re-bautizada como Don Pascual. Mangucho y Meneca son dos niños que están siempre a la caza de la próxima travesura. Pareja incipiente de seudonoviecillos, Mangucho por su parte trabaja en el almacén de Don Pascual, un descendiente de italianos gordo y de nariz colorada que siempre intenta, como el buen estereotipo del almacenero que luego será continuado en Don Manolo, ganar la mayor cantidad de dinero. Mangucho trabaja desde las 8 de la mañana (aunque muchas veces llega tarde) lo cual nos lleva a preguntarnos en que momento concurre a la escuela. De hecho, la tira existe en un universo en el cual la educación formal no existe, pero el trabajo es una constante de la vida infantil. El otro lugar para los niños, al menos en los inicios, es la calle. Battaglia dibuja una Buenos Aires de calles empedradas y garitas de ladrillo para el vigilante de la esquina, de buzones colorados y almacenes que guardan los productos en bolsas y barriles. Sus calles son anchas y siempre tienen fondos interesantes y el barrio, donde transcurren las aventuras, es tranquilo y repleto de niños, en lo que parece ser su hábitat natural.

Battaglia realiza una imperceptible combinación entre detalles gráficos "standard" que se habían convertido ya parte del lenguaje tradicional de la historieta de niños traviesos con características propias de un Buenos Aires observado y costumbrista. Como destacaba en una nota publicada en la revista Dibujantes, lo más cercano que contamos a un testimonio de su filosofía artística:

...el mono cómico es la exageración al máximo con respecto a un hombre normal dibujado. De ahí que en lo primero que pienso cuando realizo una historieta es en humanizar lo más posible a mis personajes. Tratándose de un humorismo alocado y extravagante como el que cultivo, ello es primordial.

Un argumento disparatado, de situaciones exageradas; pero sin humanidad, tanto en la estructura del mono, como en la acción, nunca podrá alcanzar el éxito. (Battaglia, 1953, p. 5)

Es real que Battaglia, en Mangucho y Meneca, construye un tipo de humor y de narratividad donde lo disparatado y lo absurdo es lo que prima. Pero, además, Battaglia dibuja sus páginas con una densidad gráfica y humorística enorme. Una vez que la tira se asienta y encuentra un ritmo y un estilo con el cual está cómodo, se multiplican la cantidad de chistes por cuadrito, de ocurrencias y de giros absurdos y exageraciones. Battaglia trabaja sobre un montaje de situaciones humorísticas sobre situaciones humorísticas en progresión aritmética, una comedia de enredos en donde cada personaje puede causar la desgracia de otro, llevando a que cada media página de Mangucho y Meneca (que se publicaba en la retiración de contratapa de Patoruzú, compartiendo espacio con Little lodine al principio y luego con El Gnomo Pimentón) reclame una lectura atenta y lenta y que los giros y contragiros de la trama se compriman en espacios que parecen más prolongados de lo que son. 
Pero detengámonos un segundo en la construcción y características de la trama que traza la tira. En un principio, nos es presentada con un par de aventuras. En la primera Mangucho, Meneca y Don Pascual tienen que recuperar un tesoro encontrado en el sótano del almacén que les es robado por el malvado Poroto (Patoruzito \#1-9, 1945). En la segunda se nos presenta a Agustín, el terrible y malvado primo loco de Don Pascual, y la historia trata acerca de cómo quiere asesinarlo y adquirir el almacén (él también tuvo uno, pero fracasó por su mal genio) (Patoruzito \#10-16, 1946). A partir de allí los siguientes dos años se dedicará a contar breves historias sin continuidad en entregas individuales, en las cuales en general Mangucho y Meneca le hacen alguna jugarreta a Don Pascual, o él ejerce sucumbe al egoismo y encuentra su justo castigo, en una lógica muy similar a la de los Katzenjammer Kids y el Capitán, obvia inspiración de estos primeros años.

Pero a medida que avanzan las tiras Battaglia va construyendo un universo. Primero con Zaza, la novia de Don Pascual, mujer gigante de busto imponente que fuma tarugos de cigarro. Luego el Dr. Pulgueti, linyera narigón y de pies largos que se encuentra infestado de pulgas a las cuales entrena o contagia al resto de los personajes. Después Taraleti, el mensajero del correo, de dientes prominentes y habla graciosa. Finalmente el Sapo Felipe, mascota en todo inesperada y absurda, que siempre usa un moño. Esta es una forma a través de la cual Battaglia construye continuidad y espesor incluso en tiras inconexas unas de las otras. Un elenco de personajes cada vez mayor implica una variabilidad cada vez mayor de interacciones, de chistes, de vuelcos en la fortuna y caída en el infortunio.

Una vez que el elenco se encuentra fuertemente establecido Battaglia se embarca en aventuras extensas. La primera ve a los protagonistas envueltos en la búsqueda de un tesoro enterrado por un antepasado pirata de Don Pascual (Patoruzito \#130-149, 1948). Pero, una vez descubierto, se revela que en realidad es un cuadro de una mujer muy espantosa, la amada del pirata. El cuadro, entonces, se torna en un objeto estético pero también político. Por un lado un grupo de críticos descubren que es la última obra conocida de Max Turbio, pintor reconocido. Esto vuelve al cuadro valiosísimo y se suceden una serie de peripecias en las cuales diversos delincuentes quieren robárselo a Pascual. Luego cae en posesión de Agustín, el primo demente, quién emplea el gran poder horroroso de la pintura para volverse emperador del barrio y de la Argentina.

En una secuencia que por momentos parecería ser una velada parodia del gobierno peronista de turno, Battaglia muestra a Agustín subido encima de una tarima con cientos de personas aclamándolo por miedo al cuadro. Asimismo, se rodea de chupamedias que Battaglia dibuja con una media literal en la boca. La multitud en más de una ocasión se encuentra presta a liquidar a nuestros héroes, pero finalmente prevalecen. (Ver Figura 2) En las últimas dos tiras, en un acto de vanguardismo para la época, el mismo Battaglia se hace presente, señalando su firma como marca de autoridad, y opina sobre la calidad del cuadro y la belleza de la mujer, aniquilando su poder negativo, ejerciendo su derecho a sanción y cambio de aquello que había inventado (Ver Figura 3). A partir de allí, el ritmo se encontraba marcado. Battaglia alternará narrativas de una sola plancha en donde la gracia reside en algún reverso de la fortuna marcado por la violencia cómica con aventuras más largas en las que se busca algún tesoro, se enfrenta algún malvado o se descubre una tecnología o elemento misterioso que cambia la fortuna de sus protagonistas. En una de ellas viajan a una difusa representación de Arabia ya que un maharajá ha secuestrado a Meneca (Patoruzito \#159-170, 1948-1949). En otra la aventura los lleva al Amazonas, en búsqueda de una ciudad llena de oro (Patoruzito \#174-186, 1949).

Battaglia no escapa, sin embargo, a cierto exotismo racista que caracterizaba también a las tiras clásicas de Quinterno. Los árabes son cuasi salvajes que tienen a sus mujeres atadas. Mujeres que, además, son muy feas. 
Las amazonas y los indígenas también son bestias, con rasgos exagerados, labios gigantes y huesos atados en sus cabellos. Una caricatura judía, narigona y de largos cabellos y sombrero negro, hace su aparición con frecuencia, siempre en la situación de un vendedor inescrupuloso que regatea y negocia productos a precios mucho mayores de los reales.

Pero, más allá de estos detalles que se ven violentos a los ojos contemporáneos y que en ese entonces eran parte del discurso gráfico general de las tiras de prensa y los dibujos animados, Battaglia culmina la transición de una tira de niños traviesos basada en la repetición de un esquema de broma y venganza, a una tira de aventuras en la cual la narración también se va construyendo al ritmo de la publicación semanal y sin dejar de lado una gran cantidad de chistes individuales por entrega.

Por supuesto que ciertas características estructurales que desatan o sostienen el relato de las aventuras se repiten (el tío pirata de Pascual es un clásico) pero lo interesante es como son suplementados con una batería de detalles gráficos y de innovaciones continuas en la presentación de nuevos personajes, en la manera de dibujar y en los recursos empleados para narrar. Battaglia dibuja muchos chistecitos en el fondo de la tira ocurren en el trasfondo de la tira, y los va repite, pero esta repetición se torna teatro del absurdo y cada nueva iteración profundiza nuestra desorientación y nuestra risa. Uno de los más conocidos de estos muestra a dos mozos gallegos que charlan. Uno de ellos le pregunta al otro "Are you Manolo?" a lo que el otro contesta "I am". Rara avis, incomprensible, desconectada de lo que sucede a su alrededor, se torna contraseña entre el autor y el lector y signo de que en el mundo de Battaglia todo puede suceder.

Como dicen Trillo y Bróccoli “Battaglia es exagerado, surrealista, vital” (1972, p. 73). Y es este surrealismo el que le permite abandonar el costumbrismo y la repetición para construir una historieta que, como Langostino, pareciera estar construyéndose frente a nuestros ojos continuamente. A menudo las tiras no cuentan con remate y muchas veces la situación cambia de cuadrito a cuadrito en una sobrecarga de información. Como Langostino, abundan las inversiones de carácter y fortuna y las apariciones providenciales. Son, además, frecuentes los casos en los que Battaglia quiebra el registro de la narración introduciendo sueños de alguno de sus personajes. Lo radical de su propuesta es que no señala de ninguna manera, ni gráfica ni verbalmente, que ellos son sueños sino solo hasta su desenlace. Debido a la característica alocada de la narrativa usual de Battaglia, nos encontramos a menudo leyendo esas secuencias e intentando dirimir si pertenecen al orden de la "realidad" de la historieta o a su fantasía.

En definitiva, encontramos tanto en Langostino como en Mangucho y Meneca un equilibrio entre el esquematismo y la experimentación, entre la repetición y la construcción de una multiplicidad de sucesos encadenados. La solución que ambos encuentran para romper los esquemas impuestos por la factoría Quinterno es la aventura, pero la aventura entendida como una concatenación de eventos que no necesariamente construyen una narrativa coherente, sino que se van agregando en una tira infinita. Sus personajes no regresan a casa, no almuerzan, no reposan. Están siempre arrojados por fuerzas externas o por su propio deseo a la búsqueda de la próxima acción. Frente a las aspiraciones de gran industria y producción masiva y controlada de Quinterno, tanto Battaglia como Ferro encuentran la libertad en el abandono de la narrativa iterativa y del planeamiento. Además, ambos encuentran esta libertad en la experimentación con el dibujo. Battaglia con sus cuerpos enloquecidos y Ferro con sus continuas transformaciones de los espacios y las tierras y su desfile de habitantes de otros mundos. Ambos eran empleados y colaboradores, bien pagos, que 
cumplían un horario, pero encontraron en estos personajes y una manera de plantear la fuga que el dibujo siempre representó, en primera instancia, para todo creador.

\section{Bibliografía}

Battaglia, R. (1953). "Sentido gráfico y humanidad son la base del dibujo humorístico". En: Dibujantes \#2. Buenos Aires: sin editorial registrada.

Eco, U. (1965/1984). Apocalípticos e Integrados. Madrid: Lumen.

Ferro, E. (1986). “Langostino vuelve a navegar”. En: Crisis \#41. Buenos Aires: Ideas, Letras, Artes en la Crisis. Recuperado de: http://sonrisasargentinas.blogspot.com.ar/2015/12/ langostino-navega-por-don-gregorio.html

Harvey, R. C. (1994). The Art of the Funnies. Jackson: University Press of Mississippi.

Masotta, O. (2011). Conciencia y estructura. Buenos Aires: Eterna Cadencia.

Patoruzito (1945-1950). Buenos Aires: Editorial Dante Quinterno.

Reggiani, F. (2012). "La única verdad es la realidad: apuntes sobre la noción de historieta realista”. En: Cultura, lenguaje, representación. Revista de estudios culturales de la Universitat Jaume I, Vol. 10.

Sasturain, J. (1980). “Ferro, dibujate algo”. En Superhumor \#2. Buenos Aires: Ediciones de la Urraca.

Steimberg, O. (1977/2013). Leyendo Historietas. Buenos Aires: Eterna Cadencia.

Trillo, C. \& Broccoli, A. (1972). El humor gráfico. Buenos Aires: Centro Editor de América Latina.

Vazquez, L. (2012). “Un modelo a imitar: Disney en Ezeiza y el proyecto empresarial de Dante Quinterno”. En: Antíteses v. 5 n. 9.

Abstract: The appearance of the magazine Patoruzú in 1936 marks the beginning of one of the most successful cartoon publishers in Argentina, that commanded by Dante Quinterno. For a long time the company founded by him would be the paradigm of a modern organization of the work of the vignettes and of an aesthetic line: rounded drawings, clear lines, friendly characters, stories where good always triumphs. In 1945, the businessman decided to expand his line with the addition of a comic magazine aimed at the little ones: Patoruzito. This was presented as a magazine that wanted to offer on each page a new adventure, stories that continued eternally, untiring characters. Initially it combined national and American material, acquired through syndicates. But soon he developed his own star cartoonists, among them the duo we are dealing with here: Eduardo Ferro and Roberto Battaglia.

Key words: Eduardo Ferro - Roberto Battaglia - Patoruzito.

Resumo: A aparição da revista Patoruzú em 1936 marca o início de uma das editoras de desenhos mais bem sucedidas da Argentina, com o comando de Dante Quinterno. Durante muito tempo, a empresa fundada por ele seria o paradigma de uma organização moderna do trabalho das vinhetas e de uma linha estética: desenhos 
arredondados, linhas claras, personagens amigáveis, histórias onde o bem sempre triunfa. Em 1945, o empresário decidiu expandir sua linha com a adição de uma revista de quadrinhos destinada aos mais pequenos: Patoruzito. Isto foi apresentado como uma revista que queria oferecer em cada página uma nova aventura, histórias que continuavam eternamente, personagens incansáveis. Inicialmente, combinou material nacional e americano, adquirido através de sindicatos. Mas logo ele desenvolveu seus próprios cartunistas estrela, entre eles a dupla com a qual estamos lidando: Eduardo Ferro e Roberto Battaglia.

Palavras chave: Eduardo Ferro - Roberto Battaglia - Patoruzito.

[Las traducciones de los abstracts al inglés y portugués fueron supervisadas por el autor de cada artículo]

La historia interminable: Langostino y Mangucho y Meneca en Patoruzito (1945-1950) fue publicado de la página 57 a página70 en Cuadernos del Centro de Estudios de Diseño y Comunicación №74 